\title{
Contribución al estudio de la materia médica peruana
}

\author{
POR EL DR. ANGEL MALDONADO \\ Profesor de Maleria Médica en la Sección de Farnacia.
}

\section{AZAIFRAN DELL, NORTE}

Sin: Azafrán americano.

Origen.-.Estas flores proceden del Carthamus linctorius L., de la familia de las Compuestas. Planta herbácea, anual, con hojas alternas pinnarilobuladas y espinosas.

Originaria del Oriente; cultivada por sus llores, cmplcadas en sustitución del azafrán (Croccus salictus L). o para sofisticar a estc.

Se le cultiva en Italia, Sur cle Rusia, Asia, España, Francia, Hungría, Estados Unidos de América, China, la Inclid, región del Nilo y en muchos otros paises del globo.

En el Perú se le cultiva en los valles de la costa de varias provincias del Norte; en a comercio se le conoce con el nombre de Azafrán del Norle.

Historia.--Esta planta se cultiva en el Antiguo Contincnte, desde épocas remotas, habiéndose comprohado por UNGER que "las vendas que rodean las momias de los antiguos egipcianos, están teñidas de Cartamo" (1); en la India también se le cultiva de antiguo, denominándosele en Sanscrito. Cusumbha y kamalottara (1); "los chinc:s han recibido el Cártamo solamente en el 11 siglo antes de Jesucristo» (1). 
La voz genérica Carthamus, deriva de la voz Arahe Kurtum, (1) una de las muchas voces, con que estos designaron a esta planta.

Caracteres exteriores (A. Maldonado y N. Esposto).-Flores hermafroditas, flosculosas, formadas de un tubo muy delgado, que alcanza unos 15 m.m. de longitud (Fig. 1): limbo campanulado, formado por cinco lascíneas lineares, lanceoladas, de unos $7 \mathrm{~mm}$. de largo por $1 \mathrm{~m} . \mathrm{m}$. de ancho más o menos, y generalmente encarrujadas por contracción: lascíneas de consistencia de finas membranas, provistas de dos delgadas y finas nervaduras marginales que convergen en el ápice; estambres en núnci: o de cinco, soldados por sus anteras, formando un tubo delgado de unos 6 m.m. de largo; ovario (que en la droga del comercio no existe) infero, uniovulado, provisto de un largo y delgado estilo que termina en un estigma delgado porriforme.

Las flores en su conjunto tienen un color amarillo anaranjado más o menos rojizo; las anteras son de color amarillo pajizo; el estigma que sobresale en casi toda su longitud del tubo formado por las anteras, es de color amarillo grisáceo; el olor es suave, particular, se acentúa frotando las flores entre las manos; el sahor es dél.ilmente amargo y aromático; tiñe de amarillo la saliva.

El polvo, con el ácido sulfúrico concentrado toma una coloración hruná.

La droga quc circula en el comercio, está constituida únicamente por lias flores (generalmente comprimidas) sin el raceptáculo.

Composición quimica.-Las llores procedentes de Alejandría, contienen según DUFOuR

p. 100

Agua ......................... 6.2.

Polvos, compuestos de restos de plantas y de arena... 3.4.

Alhúmina vegetal... ............... 5.5 .

Matcria colorante amarilla, sulfato de calcio y' sulfato de potasio ....................24.4.

Materia colorante amarilla, cloruro de potasio $y \quad \therefore . .$. acetato de potasio................. +.2.

Resina.............................. 0.3.

Cera......................... 0.9.

Materia colorante roja................ 0.5.

Celulosa ...................... 49.6.

Alúmina y magnesia................... 0.5.

Oxido rojo de hierro................... 0.2.

Arena ... ... ...................... 1.2. 


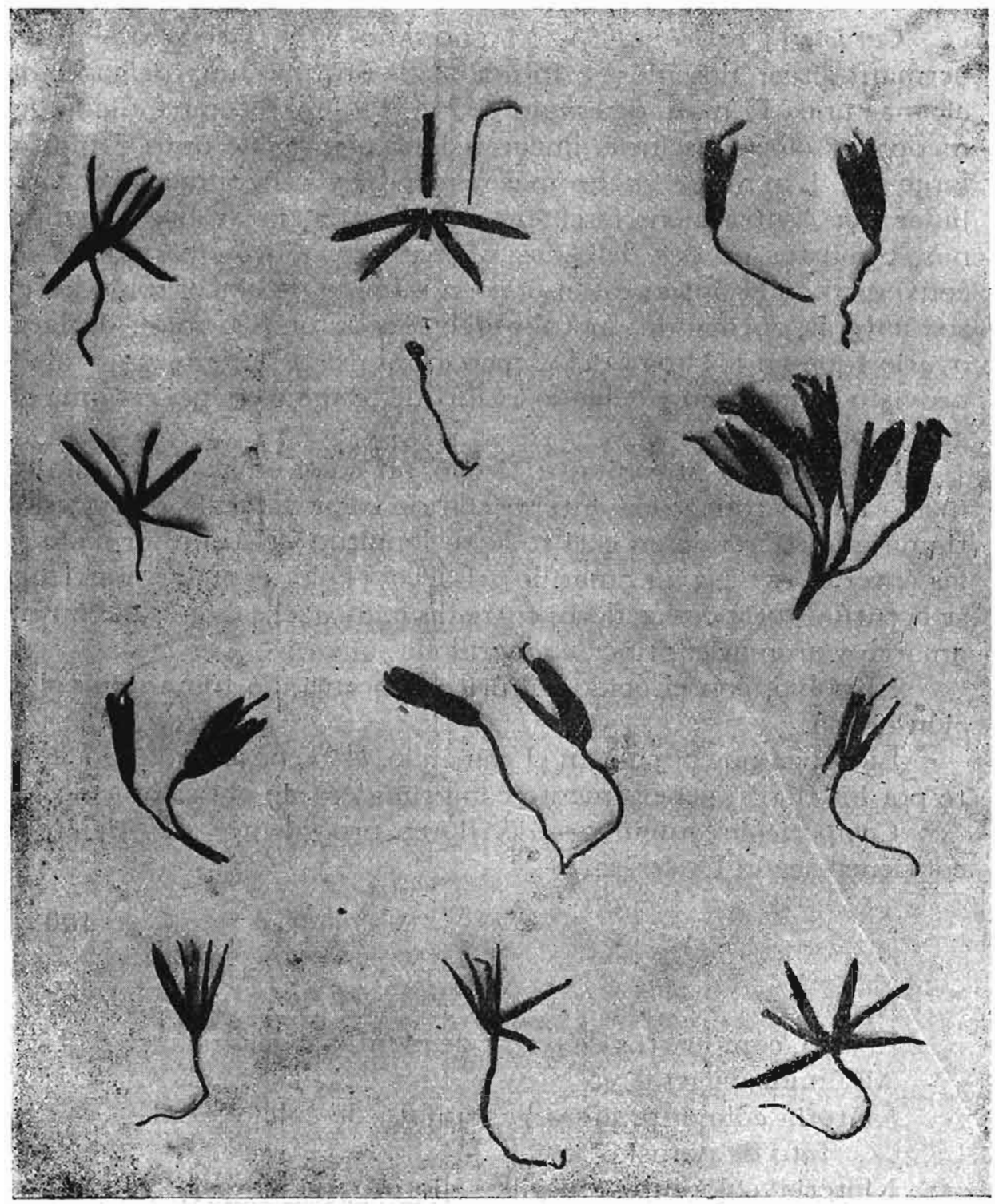

Fig: 1

Carthamus 'inctoritis' $L$.

Flores 
Las flores según SALVETAT, están constituídas por:

Materia colorante amarilla soluble .....26.1.....36.0.

Carthamina (ácido carthámico). . ...... $0.3 \ldots \ldots .0 .6$.

Materia extractiva ............ 3.6....6.5.

Albúmina ................. $1.5 \ldots \ldots 8.0$.

Cera..................... $0.6 \ldots \ldots 1.5$.

Celulosa y pectina . . . . . . . . $38,4 \ldots \ldots 56,0$.

Sílice.................... $1 . . \ldots \ldots 8.4$

Oxido de hierro, alúmina y óxido dé manganeso................ $0.4 \ldots \ldots 4.6$.

La carthamina, según SCHLIEPER, tiene por fórmula $\mathrm{C}^{14} \mathrm{H}^{16} \mathrm{O}^{7}$ : se presenta bajo la forma de escamas de color rojo, con reflejos verdosos; soluble en los álcalis caústicos y carbonatados, con coloración rojo amarillenta; soluble en el alcohol, con coloración rojo cereza; soluble en el ácido sulfúrico concentrado, con coloración roja; insoluble en el éter sulfúrico y poco soluble en el agua.

El polvo de flores de Cártamo está caracterizado: \&1. Por la presencia, en la mayor parte de sus elementos, de canales secretores llenos de una materia oleoresinosa bruna, cuyo tinte resiste bastante largo tiempo a la acción del hipoclorito de sodio: 2. Por la presencia de restos del estilo y del estigma, que están erizados de papilas cónicas; $3 .^{\circ}$ Por la presencia de granos de polen igualmente adornados de pequeños tubérculos llevando tres poros bien aparentes" (2).

Usos:-En las farmacias, se le emplea para sofisticar el azafrán verdadero (Croccus sativus $L$ ).

En la economía doméstica, le dan las mismas aplicaciones que a) azafrán verdadero.

BiBilografía

1. Candolle Alph. de.-Origine des Plantes Cultivécs.-París. 1886.

2. Collin Euc.-Du safran et de ses falsifications.- . Journal de Pharmacie et de Chimies. Septima Serie. Tomo 11. Paris, 1910. 


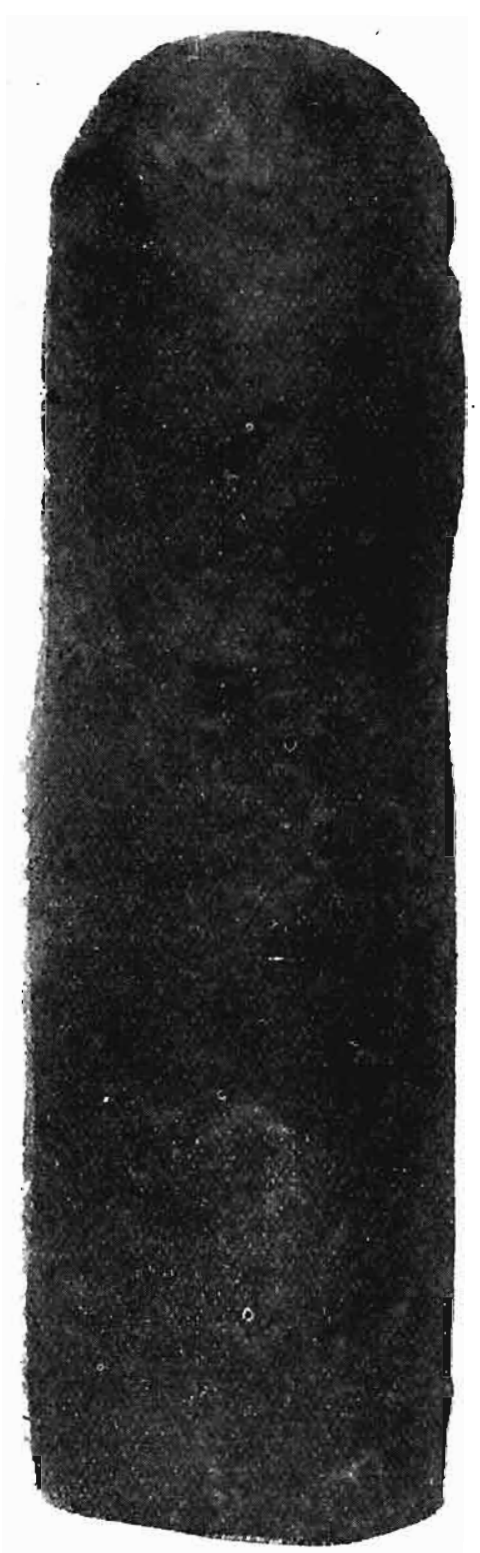

$1: i$. 2

lieraraná

Nlusan R:imondi

\section{GUARANA}

Origen--Procede de las semillas de la Palillinia sorbilis Martius. planted de la familia de las Sapindáceas. indigena de la región montañosa de la Américá del Sur; encontrándosele pril:cipa!mentc en las scivas del río Amazonas y de sus trihutarios.

I. a muestra que estudiamos la hemos encontrado en e! Afuseo Raimondi.

Caracteres exteriores.--Se presenta en cilindios. (Fig. 2) cortados por un lado y redondeados por el otro; su superficie es de color negrúzco, semibrillance, en parce lisa y en parte grumoicle: pesados, duros y cie consistencia pétrea: se parten anon suma facilidaul; su fractura es de aspecto resinnide. hrillante en ia periferia y semi-hriliante an cl resto. de color íerruginoso oscuro. picsentando caridades de difcrentes formas que no vieren a ser sino los moldes de fragmencos de semillas clespicndidas en el momento de la liacura: su longicul es de $1+\mathrm{cm}$. por $37 \mathrm{~mm}$. de diámerro: su olor es aromático poco pronunciacto: su sahor recuereld micho a) del cacao, sicndo algo ascringente.

Preparación.- Los indios Cillaranis emplean el siguiente procedimiento las semillas después de lavadas cuidaulosamente. son torrelactalas a fuego lento. clurance seis horas: al cabo de las cuales se incroalucen en sacos. los que son apaleados. para despojarlas de la testa pupirácéd. Yobtener las almendras: las que en una picdra calentada. son reduciclas a lina pasta con ayuda del agrua: pasta a la que a veces añaten 
cacao y harina de yuca, a esta pasta le dan en seguida la forma de cilindros que secan al sol, o colocan durance varias semanas sobre piedras ligeramente calentadas; y sin ninguna otra manipulación se expiden al comercio. Este procedimiento con ligeras variantes es el empleado en otras regiones.

Composición química.-Contiene según varios autores: almidôn; goma; substancia resinosa, de color bruno-rojizo; esencias; substancia grasa; clorófila; ácido catecu-tánico; y 2.5-5grs., por ciento, de caleína, combinada al ácido catecú-tánico.

En algunas muestras también han encontrado, varios autores. saponina y catequina.

Usos.-Se le emplea como astringente, por el ácido catecu-tánico que contiene: y en las hemicráneas, por la cafeína que contiene.

Las semillas de la Paullinia sorbilis Martius, están consideradas como alimento de ahorro. como la nuez de kola.

\section{ACHIOTE}

Sin: Achote. Terre de la Vontelle Orléans, Urucu, Pigmentum urucu (DORVAILT).

Orlean, Arnotta. Alemán; Annoto, Arnotlo, lnglés; Oriana, Italiano: Achiole. Orellana. Español: Rocou. Francés (Dorvault).

Urucu. Tupi, (iuaraní, Braził; Jox, Motocintleca; Có, Páez: Ox. Jacalteca: Quitá, Chicomucelteca; Sanunchi, Cidyapa; Shonguó, Térratra: Iica, Chilucha: Onotépoui, Ouayana; Onooto zoco. Aparai.

Pllchole, Plliholi. Antis; Masé. Atasé, Conihos; Apisiri, Chontaquirs: Apijiri. Piro: Pulzuli, Potroti, Potochi, Campa; Atasé, Sipilon: V'chimi. Yuracaré; Achihuiti (Cuzco). Perú.

()risen. ... Fistas semillas proceden de la Bixa Orellana l.. de la familia de las Bixúceas, plantia cultivada principalmonte en Jamaica, Antillas Francesas. Brazil. Cuayana Francesa, Java, Ceylán, Madras, ctci. y en toda la América tropical.

"l.a Bixa Orellana L., es originaria de la América del Sur. Aun hoy se encuentra al estado silvestre, en Panamá, en Colombia y en el Perú, una variedad platycarpa Warh (Bixa Urucurana Willd), cle pequcrias cápsulas obtusas con granos pobres en materia colorante. la que según M. DE WILDEMAN, sería el ancestral de las variedacles y formas actualmente cultivadas $(1+)$.

Hisforia.-- La materia colorante suministrada por el achiote es empleada de muy antiguo por los naturales de la América tropical: 
en Cuba. lo empleaban con el nombre de bija o bixa, para pintarse el cuerpo, sobre cuyo fondo trazaban líneas o dibujos con un tinte negrúzco que llamaban jagua (5) (6), xas mujeres se (untaban) con estos colores para danzar sus areitos y porque aprietan las carnes* (5); el mismo uso daban al achiote en las Antillas y en el Brazil (13), siendo probable que en muchos otros pueblos de la América tropical tuvieran la misma costumbre de pintarse el cuerpo con achiote; el achiote en México se empleaba tanto para la tintorería (7), cuanto para la pintura (8), en las que alcanzaron tan grandes progresos

Fernandez de Oviedo y VAldes, dice que en la *Isla Española", hacían con las semillas, "unas pelotas los indios con que después se pintan las caras, e lo mezclan ciertas gomas, e se hacen unas pinturas como bermellon fino, e de aquella color se pintan las caras y el cuerpo, de tan buena gracia que parescen al mismo diablo. E las indias hacen lo mismo quando quieren hacer sus fiestas e areytos o bayles, y los indios, quando quieren parescer bien, e quando van a pelear, por parescer feroces....... e aun tiene un bien o sirve a los indios en esto: que quando están assi pintados, aunquelos hieran, como es la pintura colorada e de la color que le sale la sangre, ro desmayan tanto como los que no están pintados de aquie!'a color roxa o sanguínea; y ellos atribúyenlo a la virtud cle la bixa, e no es sino por ser assi de color sanguínea (16).

Según el Padre C.OBo, el achiote también servía "para dar color al chocolate y a los guisados" (15) y no era "menos provechoso para el uso de la medicina, porque cura las cámaras de sangre, provoca la orina y mitiga la sed».

La voz Achiote es un cubanismo, según las opiniones del Padre Cobo (15) y de JUAN de Arona.

Las voces Achiote, Achote, Achiotl o Achiyutl con que se designa a estas semillas, son Nahuatlismos, según la opinión de FERnandez FERr.az (12) y para quien el análisis de estas voces "es bastante oscuro". pudiendo venir de: "achlli=semilla +ivotia =brillar, puesto que debió de usarse como colorete para las mejillas y como pintura para !a alfarería, telas y mucbles; o de atl=agua + chia (semilla oleaginosa por excelencia) por grasa +oll (camino) usado como terminal genérico, significando entónces semilla que engrasa el agua, propiedad, que tiene en efecto el achiote» (12).

Puede consultarsc también (9), (10), (11) y (13)

Grandes cantidades de achiote, se exportaron de América a España, desde los primeros años de la conquista; y según los Aranceles Reuies de 1778. se avalúaba "cada quintal (en) mil y seiscientos reales"; estando libre de derechos de entrada en España. 
El achiote fué una de las primeras plantas, llevadas de América "al medio día del Asia y al Africa". en donde se han aclimatado tan bien, al punto de parecer indígena de esos cöntinentes.

Caracteres exteriores. (A. Maldonado y N. Esposto):-El fruto es cepsular (Fig: 3), acorazonado, prolongado en la base en un pequeño carpóforo; se abre en dos valvas, cuya dehiscencia es loculicida; de unos 4 a $5 \mathrm{~cm}$. de largo, por unos $35 \mathrm{~m} . \mathrm{m}$. de ancho y cerca de $2 \mathrm{~cm}$. de espesor; de color rojizo ferruginoso obscuro; la superficie presenta pelos de unos $8 \mathrm{~m}$.m. de longitud, gruesos, duros, resistentes y bastante ralos; las valvas o ventallas del fruto, son de consistencia pergamínácea, con el endocarpo muy delgado y separado naturalmente del mesocarpo casi en su totalidad.

Las semillas están insertadas a lo largo de dos placentas parietales, y dispuestas en dirección más o menos horizontal, en número de 60 , más o menos en cada fruto.

Las semillas, son piriformes, achatadas en su base: a veces provistas de un largo funículo, bastante grueso y consistente, disciforme en su extremidad; la semilla está recorrida por un surco muy fronunciado desde la base hasta el vértice y con dos depresiones o abolladuras obscuramente triangulares, a los costados; en el centro de la base existe una placa laminar, de color amarillo pajizo obscuro, lustrosa, con centro negrúzco, su consistencia es pergaminácea, su contorno es redondeado ligeramente lobulado, provista de una pequeña prolongación dirigida hacia el surco.

Las semillas están cubiertas de una materia colorante, de aspecto grasoso, de color rojo ladrillo oscuro; se adhieren a los dedos cuando se les estruja, dejando una mancha rojisa azafranada; el olor es particular, terebintáceo; su sabor es un tanto amargo dejando en la hoca una sensación un poco desagradable, la saliva se enturbia y es de color rojo ladrillo; la materia colorante que recubre las semillas arde con facilidad. La materia colorante que recubre las semillas es pocio soluble en el agua, la que queda teñida de amarillo por la orellina; es soluble en el ctanol de $95^{\circ}$ y en el éter sulfúrico a los que dá una coloración anaranjada; soluble en las sustancias grasas y en los álcalis cáusticos.

Composición química.- Según Chevreul, el achiote contiene dos sustancias colorantes: la bixina y la orellina.

l.a bixina responde a la fórmula $\mathrm{C}^{28} \mathrm{H}^{34} \mathrm{O}^{5}$; se presenta bajo la forma de láminas microscópicas, cuadrangulares, de color rojo oscuro con reflejos verdes violáceos; funde a $189^{\circ} \mathrm{C}$; insoluble en el agua; difícilmente soluble en el éter, alcohol y hencina; soluble en el cloroformo; soluble en el ácido sulfúrico concentrado con coloración azul, de donde el agua la precipita con coloración verde- 


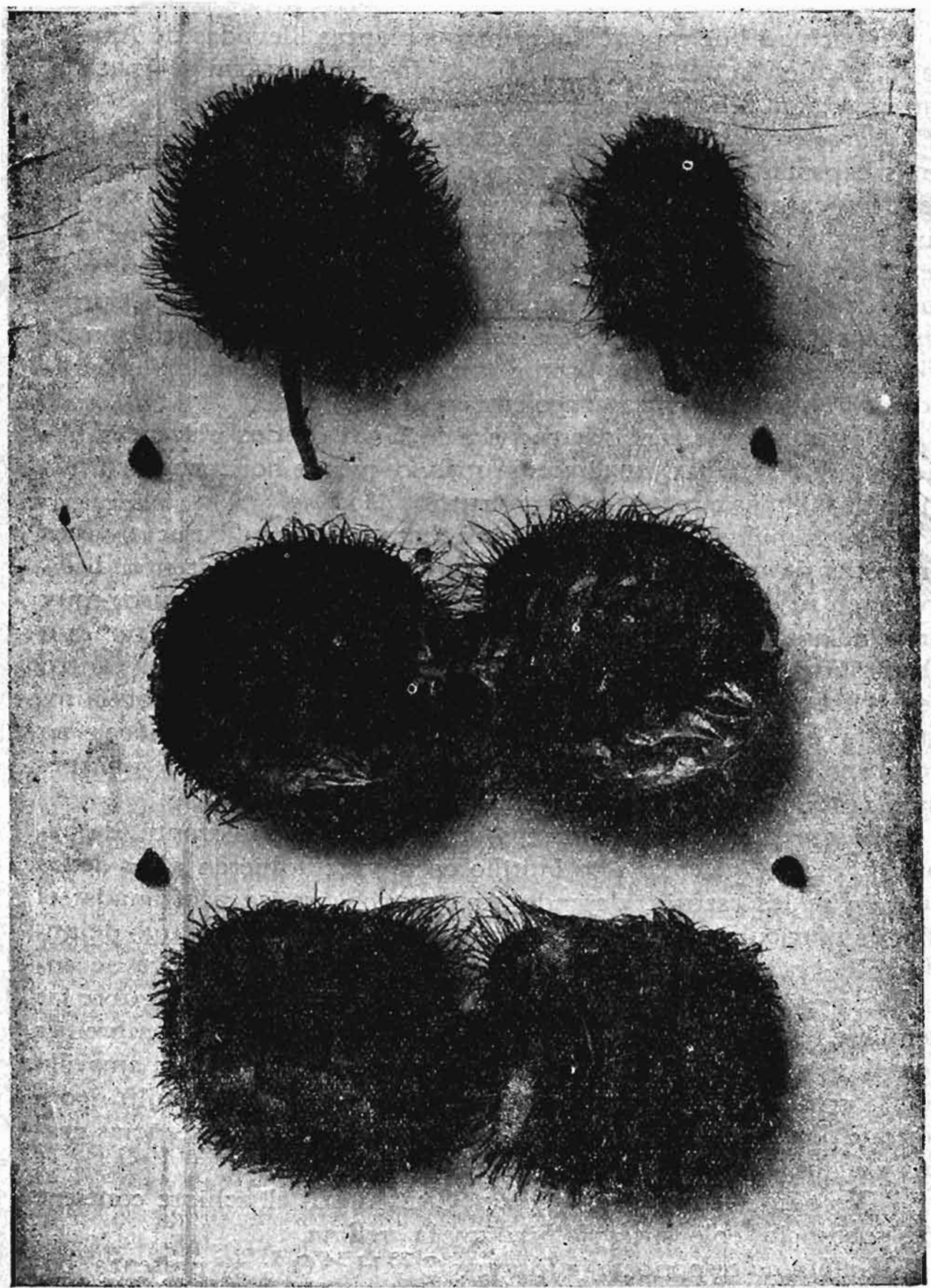

Fig. 3

Bixa orellana $L$.

Frutos

A.-Fruto visto de frente.

B.-Frito visto de costado.

C.- Semillas.

D.-Fruto abierto, visto por el lado interior.

E.-Fruto abierto, visto por el lado exterior. 
oscuro; reduce el licor de FEHLING; tiñe directamente al algodón, lana y seda (1).

La orellina es una materia colorante amarilla, soluble en el agua y en cl ctanol; poco soluble en el éter sulfúrico.

Nosotros hemos encontrado además pequeña cantidad de almidón.

Usos.--Las semillas se emplean cal como se obcienen de la planta; pero generalmente se enplea la pulpa sepalada, remojando estas con agua cáliente. friccionándolas cnere cllas, ramisando la pulpa, esprimiéndola y desccénctola a la sombra: preparase también una pasta, ortcnida molienclo, en molino de hierros las semillas humedecidas con agua.

Tanto las semillas en sí. cuanto la matcria colorante separada de ellas, asi como la pasta de las scmillas moliclas, tiene aplicación en casi todas las poblaciones del perú. principalmente en la costa y en la regrión de los bosques, para colorear varias comidas.

En la región de los bosques, los salvajes lo cmpican para colorearse la piel, principalmente la cara, en la que se hacen adilujos caprichosos que les dá aspeclo hermoso y que sirve de distintivo en los solteros" (2), estos dihujos los hacen también en las piernas y brazos y están constituídos por "rayas, puntos y dibujos caprichosos: (3) combinados con el color negruzco del huilo (Genipa sp.); los salvajes se pintan la piel no solamente para adornarse sino para preservarse de las picaduras de los mosquitos (2) y porque según ellos «infunden temor a sus enemigos" (17) y además to emplean para teñir tejidos de algodón (3), (4), o de otras libras.

\section{BiBLIOGRAFÍA}

1. Thomas V. Les plantes linctorieles, elc-Paris.

2. Strglich Cierman.- Informe de la Comisión Exploradora de las Regiones del Ucayali, Fiscarrald y Madre de Dios.-En - Ultimas Expluracioncs ordenadas por la Junta de Vías Filuviales. - l.ima, 1907.

3. Pesce LUis. - Informex. En : Ultimas Fxploraciones ordenadas por la Junta de Vias Fluviales. - Lima. 1907.

4. Fry Carlos.- La gran región de los bosques.-Rios peruanos navegables.Lima; 1889 .

5. Lopez de Gomara Francisco. - Hispania Vichix. Primera y sugunda parte de la Historia lieneral de las Indias. - En * Hist. Prim. Indias. Col. Vedia.

6. Casas Bartoiome de las.- "Hisloria de las Indias"-Madrid, 1876.

7. Clavigero Francisco Saverio.- Hisloria Anligua de Mégico. -abondres, 1826 .

8. Flores francisco A - L La medicina entre los indios mexicanos, antes de la Conquista:.-México, 1912.

9. Vargas Machuca Bernardo de.- Descripción de las Indias.-Madrid, 1872 .

10. Guzman D. J.- Botánica Industrial de Centro Américus.-En x Anales del Museo Nacional. - San Salvador. 
11. Haenke TAdeo.-. Introducción a la Hisloria Nalural de la Provincia de Cochabamba y Circunsvecinas. Con sus produccione's, - C Cochabamba, 1798.

12. Fiernandiz FrRraz Juan.- Nahuallismos de Cosla Rica.-San José de Costa Rica, 1892

13. Candolle Alph. de.-Origine des Planles Cullivéc.-París. 1886.

14. Jumelle. Henr1.-Les Cullures Coloniales.-Paris, 1916.

15. Cobo Bernabe,-Historia del Nucvo Mundo.-Sevilld, is9o.

16. Fernandez de Oviedo y Valdiz Conzalo.-Hisloria lieneral y Nalural de las Indias, elc. Madrid, 1851.

17. Raimond A.-Apuntes sobre la Provincia Litoral de Lorelo- En Gcog del Perú, por Paz Soldán.-Paris, 1862.

\section{ALMENDRAS DEL PERU}

-Sin: Almendras de Chachapoyas; Tampa ruru, Tampa, (Keshua); Ayecoc (Putumayo); Cunta-bimi (Pano). Perú.

Origen.-Proceden del Caryocar amygdaliferum Mutis; planta de la familia de las Cariocariáceas, indígena de la América tropical, encontrándosele silvestre en los bosques peruanos, principalmente en la hoya amazónica.

Historia.-Aquellas almendras de Chachapoyas, de que nos habla Herrera (1) y quien las describe del siguiente modo: «maiores que las de Caftilla, tiernas de comer, fuaves, y mantecofas: crianfe en Arboles altifimos: eftan en Erizos, maiores, y de más puntas que los de las Caftañas: los Micos, para no efpinarfe, las arrojan sobre las piedras quando eftán fecas, y las abren, y comen".

Aquellas almendras de las que Acosta (4) con tan justa razón dice: "Pero en razón de almendras, aún de frutás qualquiera, todos los árboles pueden callar con las almendras de Chachapoyas. Es la fruta más delicada, y regalada, y más fana, de quantas yo he vifto en Indias. Y aún vn Médico docto afirmaua que entre quantas frutas auia en Indias, y Efpaña, ninguna llegaua a la exelencia deftas almendras......... Son muy tiernas de comer : de mucho xugo y fuftancia, y mantecofas, y muy fuaues».

Aquellas almendras de las que Calancha (6) dice que: afe crian en tierras de montaña, encerradas en un obillejo de efpinas .

Aquellas Almendras de Chachapoyas de que habla el Padre CoBo (5) y de las que dice: "Son estas almendras unos erizos como los de las castañas, muy espinosos, redondos, del tamaño de una gran nuez y de un color rojo oscuro. Tienen entre las espinas, que están muy juntas, una sustancia del mismo color, a manera de corcho, pero tierna y seca, que fácilmente se desmorona y deshace. La 
coyuntura de la cáscara no la ciñe toda alrededor, como la de otras pepitas, sino que sólo corre a lo largo de punta a punta por un lado, por lo cual se abre el erizo dándole con una piedra, o para sacar entera la almendra, apretándolo en el encaje o marco de una puerta o de otra manera. Es la médula de estos erizos una pepita tres tantos mayor que las almendras comunes, muy blanca, tierna, jugosa y suave; son, en suma, estas almendras la fruta más delicada, sabrosa y sana que yo he comido en Indias; las cuales, como cosa muy preciada, se suelen enviar en presente de la provincia de Chachapoyas a esta ciudad de Lima; y confitadas, no hay colación tan regalada que con ellas se pueda comparar».

Las almendras de las que hablan los anteriores historiadores, son indudablemente aquellas de las que nos ocupamos.

Que los Antiguos Peruanos utilizaron estas almendras está fuera de duda, pues en el Keshua tienen nombre propio y muy significativo, y consignado en los más antiguos vocabularios Keshuas publicados.

SAFFORD (8) cree que un fruto procedente de las tumbas de Ancón y colectado por Henry MEIGSS (U. S. National Museum) corresponde a esta especie; y que un huaco (vaso funerario) procedente de las tumbas de Chimbote y colectado por Manuel B. Zabaleta (Field Museum of Natural History, No. 100137) representa a este fruto; hemos examinado con sobrada atención los dibujos publicados por SAFFord y aunque este autor es serio; la verdad es que el dibujo del fruto, corresponde a otra especie del género Caryocar, y en cuanto al dibujo del huaco, parece que este no representa frutos de este género botánico.

Diego de Torres (2) consigna en su vocabulario Keshua, la voz Tampa, para designar a las «almendras de indias»; y Diego GonzAles Holguín (3) las voces Tampa ruru, para designar a las «almendras de indias». Las frases: «Ttampa tampa uma =La greña o el de efpefo cabello fin peynar; Ttampa hacha = Arbol muy enramado o no podado; Tampapachallan =El defgreñado»; y la voz «Ruru=Fruto de árbol» (3); nos dan la etimología de Tampa ruru que significaría literalmente fruto enramado o desgreñado, significando con esto que el fruto está cubierto de numerosas y largas espinas; el estudio etimológico de las voces Tampa ruru, nos prueba que las almendras de indias, son las almendras de que nos ocupamos.

Caracteres exteriores. (A. Maldonado y N. Esposto). - Se les encuentra en el comercio (Fig. 4) bajo la forma de nueces, desprovistas del epicarpo; de forma seudo-arriñonada, convexa por el lado dorsal y con una cicatríz alargada por el lado opuesto; de color canela claro; de superficie lisa, con algunas depresiones, presentan- 


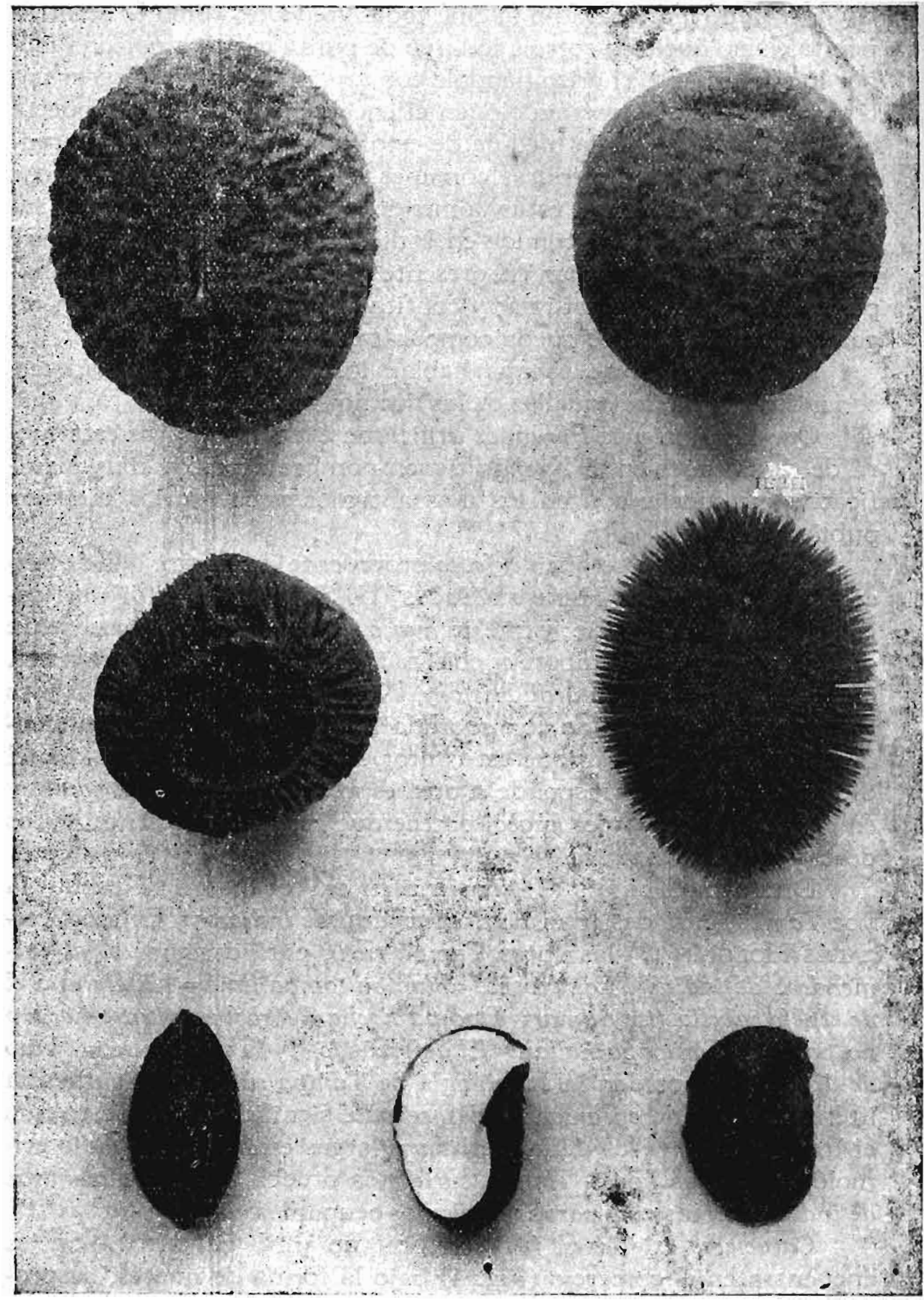

Fing. 4

Caryocar amygdaliferum Mutis Frutos

A.-Visto por el lado de la inserción. - B.-Visto por el lado opuesto. - C.-Cortado transversalmente.-D.-Despojado del mesocarpio.-E.- - a billa vista de perfil.-F. - Semilla secicjonada longitudinalmẹte.-G.-Semilla vista de costado. 
do escasas puntuaciones en la dirección de las espinas del endocarpo. Endocarpo leñoso, duro, apergaminado; liso, lustroso y de color castaño interiormente; en su parte exterior, erizado de espinas de $1 \mathrm{~cm}$. de largo y de unos $0.5 \mathrm{~m} . \mathrm{m}$. de grosor en su base, de color canela y muy puntiagudas; estando ocupado el espacio que media entre las espinas por un mesocarpo subero-esponjoso.

La almendra es de forma navicular, redondeada por una extremidad y terminada por una especie de quilla por la otra; de color rojizo-ferruginoso exteriormente; de superficie lisa o más o menos arrugada en el sentido longitudinal, según su antigüedad; presenta una mancha en el hilio, de color amarillo sucio; la longitud de la almendra alcanza $25 \mathrm{~m} . \mathrm{m}$. y su mayor ancho $15 \mathrm{~m} . \mathrm{m}$. más o menos; el tegumento seminal es delgado, bastante adherido en el lado dorsal y muy suberificado y espeso por el lado ventral; la cavidad tegume ía está ocupada por la almendra propiamente dicha. La almendra está constituída por una enorme raicecilla de color blanquecino, llena de reservas; con un surco superficial en su parte ventral superior, que está ocupado por el hipocotilo de $1 \mathrm{~cm}$. de largo más o menos por $1 \mathrm{~m} . \mathrm{m}$. 5 de grosor; el que termina por dos breves cotiledones, adosados, extendidos, delgados, de $2 \mathrm{~m} . \mathrm{m}$. de largo, por un m.m. de ancho; en el corte longitudinal, aparece claramente la línea de demarcación del cilindro central y del parénquima; su olor es suave, recuérda un poco a la nuez de coco; es muy tierna y muy suave al paladar; su sabor es oleoso, en extremo agradable; su consistencia es butirácea, se aplasta entre los dedos con gran facilidad dando gran cantidad de aceite.

Usos.-Se emplean en la alimentación; se les despoja del endocarpo solamente en el momento de usarlas.

En Moyobamba preparan con ellas una leche de almendras, que la emplean como cosmético.

\section{Bibliografía}

1. Herrera antonio de.-Hisloria de los Hechos de los Castellanos, en las Islas y Tierra-Firme de el Mar-Océano.-Madrid.

2. TORRes Dieco DE.-Vocabulario de la Lengua Quichua.

3. Gonzales Holguín Dieco- - Vocabolario de la Lengua General de todo el Perv llamada Lengva Qquichua, o del Inca.-Ciudad de los Reyes.

4. Acofta IOFEPH DE.- Historia Natural y Moral de las Indias (1590).-Madrid, 1608 .

5. Cobo Bernabe.-Historia del Nuevo Murido.-Sevilla, 1890.

6. Calancha Antonio De La.-Coronica Moralizada del Orden de San Augustin en el Perv.-Barcelona, 1638.

7. Garcilaso de la Vega.-Comenlarios Reales de los Incas.

8. SAFrord William Edwin. - Food-Plants and Texliles of Ancient America.-En Proceedings of the Nineteenth International Congress of Americanists. Washington, 1917. 


\section{PAPA SECA}

Origen.-Estos tubérculos proceden del Solanum tuberosum L., planta de la Tamilia de las Solanáceas, indígena del Perú y cultivada en muchos países del mundo.

Preparación.-Se lavan cuidadosamente los tubérculos para quitarles la tierra que tienen adherida: en seguida son hervidos en agua y cuando la epidermis se desprencle con facilidad. los retiran del agua y' a mano se la despojan; los tubérculos hervidos y desprovistos de la epidermis, los exponen a la interperie, en lugares fríos, durante varios dias hasta obtener su desecación.

Caracteres exteriores. - Estos tubérculos (Fig. 5) se presentan generalmente enteros; de consistencia córnea, semi-transparentes; de color gris más o menos morado claro o amarillento; de sabor ami-
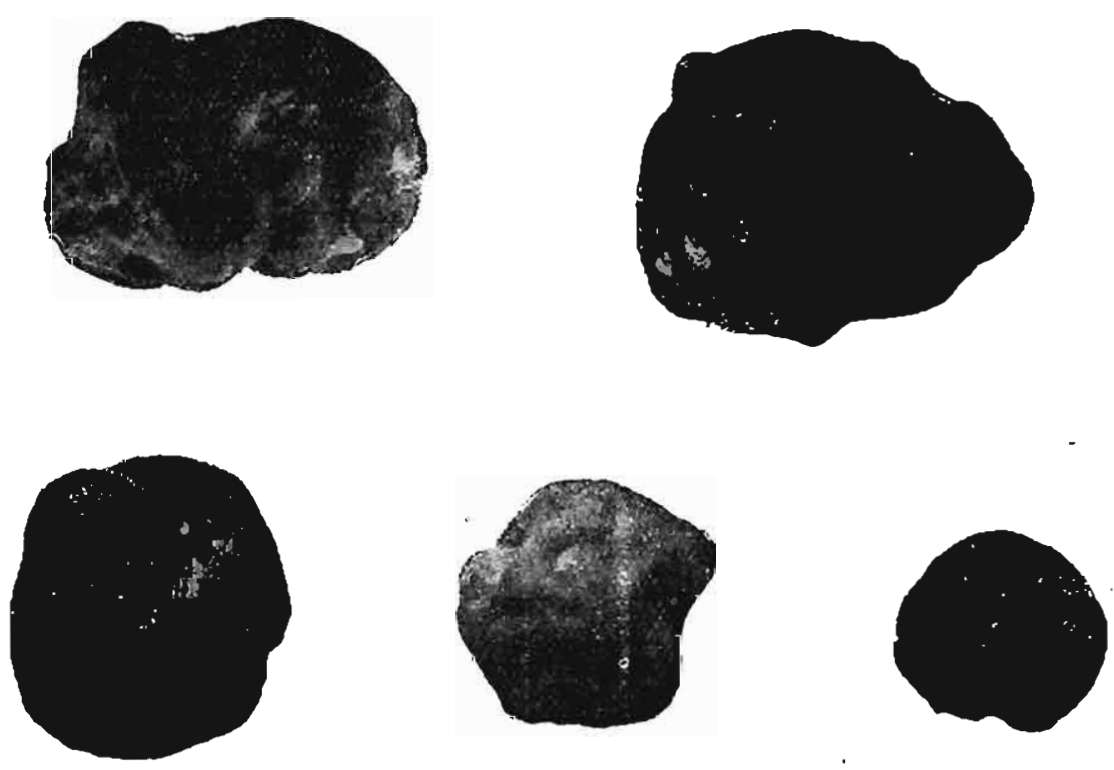

1.ig. 5

Solanum luberosum $L$.

Papa seca

Tubérculos enteros. 
láceo; inodoros; duros, rígidos; de fractura vítrea, lustrosa; de superficie semi-lustrosa, presentando en su masa rajaduras variadas de aspecto vítreo soldadas incompletamente al exterior, que le dan por supuesto un aspecto veteado; la forma recuerda a la del tubérculo natural, presentando algunas abolladuras. En el interior se encuentra una cavidad de tamaño variable, debido a la contracción de la materia amilácea hacia la pared exterior, al efectuarse la desecación; esta cavidad está tapizada por masas anfractuosas con puntas vivas; en algunos tubérculos $\mathrm{cl}$ interior está constituído por
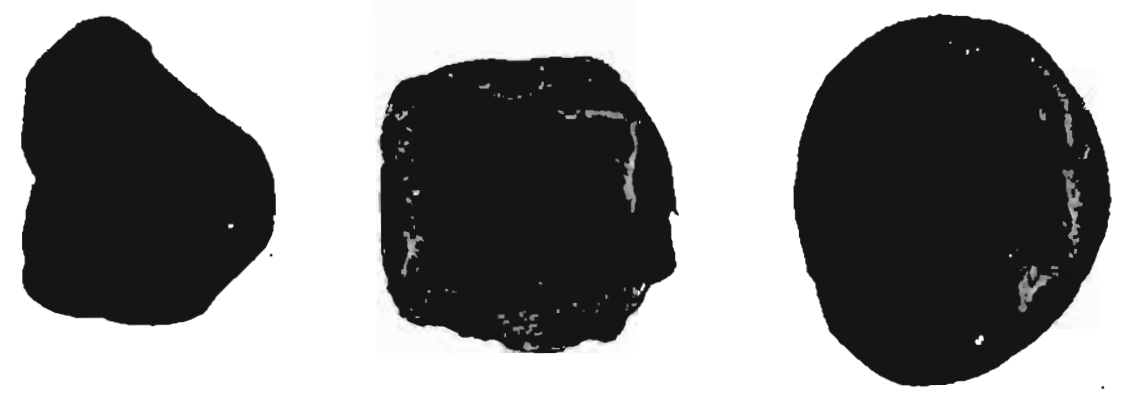

Fig. 5

Solanum tuberasum $L$.

Pepa seca

Tubérculos seccionados.

capas contínuas, con pocas resquebrajaduras, que le dan un aspecto resinoide bastante transparente. Algunos tubérculos no presentan en su superficie las pequeñas rajaduras menudas que hemos descrito y que a muchos de ellos les dá un aspecto veteado; observándose en estos la superficie lisa, uniforme, pero con algunas gruesas resquebrajaduras que ponen en comunicación el interior del tubérculo con el medio ambiente.

Los granos de almidón, se encuentran hinchados, soldados, deformados, formando un engrudo desecado, semi-transparente.

La preparación se hace en muchos pueblos de la región de la sierra, principalmente en la región del Centro.

Perú.

Usos.-Se emplea en la alimentación en muchós pueblos del 


\section{HOJAS DE SALVIA}

(irigen.--Proceden de la Salvia officinulis L., planta de la familia de las Labiadas.

Pequeño arbustito, originario de Europa; cultivado en jardines, y huertas, de las serranías peruanas, como planta esencialmente medicinal; siendo de advertir que en la costa, es una planta bastante delicada.

Caracteres exteriores.-Estas hojas son opuestas, ovalado-obliongas, gruesas, de consistencia membranácea cuando frescas, largamente pecioladas, débilmente dentadas; rugosas en la cara superior $\mathrm{y}$ abundantemente reticulado-venosas en la cara inferior; obtusas $\sigma$ subagudas en el ápice; en su parte inferior a veces están provistas deuno o dos lóbulos más o menos pronunciados, que a veces se encuentran en la proximidad de la base formando como un par de orejuelas; la base a veces es asimétrica.

El peciolo esudelgado, abundantemente velloso-pubescente, muy superficialmente acanalado, de unos $3 \mathrm{~cm}$. de largo por unos $2 \mathrm{~m} . \mathrm{m}$. de ancho en su base, de color verde blanquizco.

El limbo es de color verde en ambas caras, siendo más pálido en la cara inferior; llano o con los bordes encorvados hacia abajo.

Las nervaduras como hemos dicho, son salientes en la cara-inferior de la hoja.

Las nervaduras secundarias en relación'con la nervadura mediana son delgadas; las del $3 \mathrm{er}$. y $4 .^{\circ}$ orden, son muy numerosas y. anastomosándose entre sí, constituyen un retículo bastante tupido y saliente, dejando entre sí espacios de mallas angostas.

El limbo está cubierto en ambas caras de pelos cortos, finos, sedoso, generalmente de dos células, terminados en punta, que le dán a la planta un aspecto plateado, lo cual es todavía más aparente y brillante en las hojas. muy jóvenes.

En las dos caras de la hoja, principalmente en la inferior, se encuentran numerosas glándulas pediceladas, secretoras de aeeite esencial.

Su olor es fuerte, particular, balsámico; sabor cálido, ligeramente amargo y muy aromático.

Composición química.-De las hojas se ha retirado: resina; tanino; un principio amargo; 0.5 a 2.5 por ciento de aceite esencial; etc. 
El aceite esencial es de color amarillo verdoso; $D+15^{\circ} \mathrm{C}=0.915$ -0.925; dextrogira; neutra; soluble en el alcohol a 850; reacciona tumultuosamente con el ácido nítrico y con el yodo. Está constituída por: tuyona $\mathrm{C}^{10} \mathrm{H}^{16} \mathrm{O}$ (alrededor del $50 \%$ ), pineno, borneól y cineól.

Usos.-Se le emplea en infușión, como antiespasmódico, digestivo, estimulante y tónico.

Nota.-La medicina popular, sustituye a la salvia of icinal con las : Satoia rhombifolia R. y Pav. y S. sagittata R. y Pav. llamada vulgarmente salvia real.

Las flores de la Salvia biflora? R. Pav, fueron conocidas por los antiguos peruanos con el nombre de Nucchu; y a las que hoy suele llamarse Flores sagradas de los Incas, llamadas así porque la tradición dice que cuando los Incas salían a visitar las vastas regiones de su Imperio, regaban los visitados *los caminos por donde debía pasar (el Inca) y le derramaban sobre sus aúreas y pesadas andas, con abundantes flores del encarnado ñuccho" (2) en homenaje de reverencia, amor y respeto.

También «la flor del Nucchu, era reservada para los condenados a muerte, y echándolas sobre ellos era visto como un acto de piedad. (3).

En el drama Ollanta (5) cuando el felón RumiÑahur, se presenta ante el indomable Ollanta, le dice: «El nuevo Monarca Tupac-YuPANQUI, que ahora gobierna en el Cuzco es un tirano feróz. Vive en medio de regüeldos de sangre: degüella sin perdonar a nadie: sin saciar jamás su corazón, como el ( Nuccho) rojo que todo devora y mata en medio de su delirio».

En la actualidad en el Cuzco, "en la procesión llamada del Señor de los Temblores, se echa sobre el crucifijo tal cantidad de estas flores que el parvimento desaparece completamente y parece haber sido regado de sangre» (3).

Bibliografía

1. Cobo Branabe.-Historia del Nuevo Mundo.-Sevilla. 1890

2. Coello Alejandro.-Monogralia de dos vegelales indianos: Salvia biflora y Cassia florifera.-En "Boletín del Centro Científico"-Tomo XI -Cuzco, 1906.

3. Pacheco Zegarra.-Ollantai,-Paris, M.D.CCCLXXVIII

4. Herrera Fortunato L.-Díscurso Académico.-Cuzco, 1919

5. Ollanta o sea la Severidad de un Padre y la Clemencia déun Rey. Traducido del Quiohura al Castellano pór Jose S. Barranca.-Lima, 1868. 


\section{FLORES DE FLORIPONDIO}

Sin: Borrachero, Tonga, Floripondo. (Colombia).

Origen.--Estas flores proceden de la Datura arbórea L., planta de la familia de las Solanáceas; cultivada en las huertas de la costa y regiones muy templadas de la sierra (como Arequipa), como planta de adorno y medicinal.

Historia.-Esta planta es probablemente indígena del Perú, según las aseveraciones de Herrera (1), Calancha (2) y Совo (3); pero no hemos podido enconträr ni en los libros de historia, ni en los vocabularios Keshua, ni Aymará, el nombre indígena de ella.

Por los primitivos historiadores se le llamó Flor de campanilla (3) y más comunmente Floripondio; y en Europa la llamaban Azucena del Perú." El Padre CoBo, vió esta planta en Lima, donde "españoles e indios" la llamaban Floripondio, debiendo como el dice. haber sido traída "de alguna provincia" (3), pues nadie conocía el nombre propio de ella, sino el de Floripondio que los españoles le dieron.

Los españoles se maravillaron tanto de la hermosura de las flores, cuanto del penetrante olor de cllas (4); solían "poner estas flores en los cándeleros y dentro déllas las velas, de suerte que (servían) de candilejas para adornar los altares y las mesas (3).

*El Viforrei D. Franfifco de Toledo la embió por cola muy prefiada al Rei Don Felipe $I J$, para fus Jardines» (1).

Esta planta fué llevada a México, en época en que el Padre Bernabe Cobo vivía en el Perú (3).

Según el Padre Сово, las hojas se empleaban «para curar quebraduras (fracturas de huesos), majadas y puestas calientes en forma de emplasto sobre la rotura" (3)

Hasta el presente no se le ha encontrado, en el Perú, al estado verdaderamente salvaje.

Caracteres exteriores.-(A. Maldonado y N. Esposto)..-Cáliz gamosépalo (Fig. 6), oblicuamente hendido, terminado en punta; de color verde pálido; de consistencia membranácea; está cubierto de pelos breves exteriormente, e interiormente en la mitad superior; está recorrido por 5 nervaduras pronunciadas en la. base, y por 4 pliegues cuyo origen arranca al nivel de la hèndidura calizinal y convergen en el vértice; su longitud alcanza unos 14 centímetros.

La corola es gamopétala, infundibuliforme; de color blanco ligeramente crema en el limbo y parte ensanchada del tubo, y verde 
pálido en la parte angostada de este. Está recorrida longitudinalmente por 15 nervaduras bien pronunciadas, de las cuales 5 son principales y 10 secundarias; de color verde más o menos pronunciado en la mitad inferior y de color blanco en la mitad superior. El limbo es muy ondulado, con 5 lóbulos muy ámplios, terminados en 5 apéndices lineares vueltos hácia abajo, de unos 5 centímetros de longitud. Atundantemente vellosa en la parte externa del tuho. y: escasamente vellosid en el exterior $y$ a lo largo de las nervaduras medianas del limbo: lampiña interiormente. De consistencia membranácea, espesa y acuosa, especialemnte en la parte superior.

En el interior de la corola, existe una corola secundaris 0 para-corola de una configuración sem:jante a la de la corola propiamente dicha y además está provista de apéndices membranosos, más o menos desarrollados, laminares por su lado

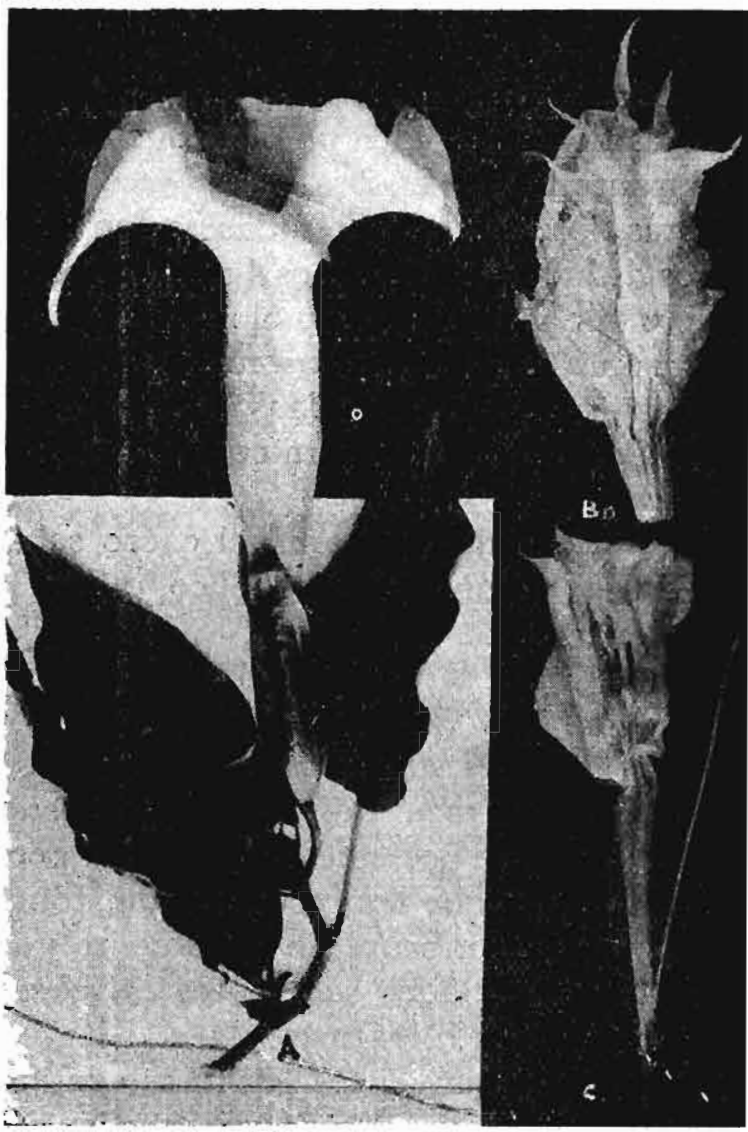

Fiy. 6

Dalura arboreal.

A. Flor.

B. y C :- Para-corol's exterior.

A lo largo del interior del tubo de la para-corola, están insertados 5 estambres, que están libres en la mitad superior del tubo, esto es donde comienza el ensanchamiento de este; los filamentos están ensanchados y son vellosos en la parte inferior y lampiños en la parte superior y terminan por 5 anteras basifijas, vellosas, provistas de dos pares de sacos polínicos cada una de ellas; los filamentos. 
en su parte inferior e interna, están recorridos por un surco longitudinal.

El ovario es bilocular, terminado en un largo estilo de 15 centímetros de longitud, el que termina en dos placas estigmáticas ablicuas convergentes y unidas en el vértice; la sección transversal del ovario es pentagonal.

La corola y la para-corola son blandas, jugosas y de sabor mucilaginoso casi insípido.

Estas flores despiden un olor que recuerda al del jazmín, sobre todie durante la noche.

Estas flores están sostenidas por un pedúnculo velloso de 5 centímetros de longitud, por unos 4 milímetros de grueso.

Usos.-Las flores por su olor son muy empleadas en la medicina poptalar, para combatir el insomnio; colocándolas en la mesa de noche debajo de la almohada.

An Colombia se prepara con los frutos un veneno llamado $\mathrm{Ca}$ cao soibanero (5).

- Lsos criminales preparan el cacao sabanero poniendo a macerar les frutos en un licor alcohólico, o bien pulverizándolos después de

* En el Cauca se hace uso de estas semillas para embriagar a las gentes sencillas, y por este procedimiento pretenden descubrir robos y averiguar los sitios donde hay tesoros ocultos. En el Ecuador las mueres de la raza indígena dan el borrachero a sus amantes, en la orreencia de que por este medio hacen perdurable su amor; lo que hay de cierto es que con esta bebida, tomada repetidas veces, los pobres indios se embrutecen totalmente y quedan a merced de sus queridas. Los antiguos sacerdotes chibchas usaban de esta planta en sus ceremoni.:s hieráticas..........

«Los envenenamientos por medio del fruto de la Datura arbórea deben atribuírse al alcaloide que contiene la planta y que en nada se distingue de la atropina».

«El veneno es suministrado a la víctima en un licor cualquiera, con suma frecuencia en la chicha o en el aguardiente. El individuo que toma algunas copas de este licor venenoso siente a los pocos minutos una sed intensa y gran sequedad en la boca, seguida bien pronto de estupor y sueño profundo que dura algunas horas. La visión se altera, las pupilas se dilatan y sobreviene la insensibilidad a la luz (síntoma característico).

«Los rateros se aprovechan del estado de estupor de las víctimas para robarlas» (5). 
Bibliografí

1. Herrera Antono de.-Historia General de los Hechos de bos Gayellanos en las Jslas y Tierra-Firme, etc.-Madrid.

2. Calancha Antonio de la.- Coronica Moralizada del Ordap de San Aagostin en el Perv.-Barcelone, 1639.

3. Cobo Bernabe.-Histaria del Nuero Minda.-Savilla, 1890.

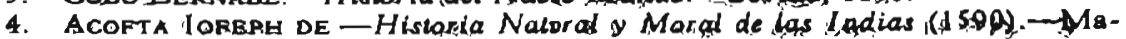
drid, 1608.

5. Lleras Codazzi Ricardo.-Envenenamiento por el frulo de la Makura arborea,L.-En r Sesiones Científicas del Centenarios.-Bogota, 1911.

6. Varcas Machuca Bernardo de.-Milicia y Descripción de las ladias Madrid, 1872. p. 113.

\section{HOJAS DE EUCALIPTUS CITRIODORA}

Origen.-Estas hojas proceden del Eucaliptus citniodora Hook, planta de la familia de las Mirtáceas; indígena de Australia; cultivada en el Perú por sus hojas aromáticas.

Caracteres exteriores. (A. Maldonado y N. Esposto). - Las thojas (Fig. 7) son lineares oblongas, dereches, so más o menos falsiformes; generalmente anchas en la parte infenior, atenuadas en la base; de 20 a 25 centímetros de largo por 13 a 27 m.m. de ancho. La nervadura mediana de estas hojas, es'sobresaliente en ambas caras, wipicamente penninervia; las nervaduras secundarias terminan en una delgada nervadura marginal, que recorre todo el borde del limbo. Entre la nervadura marginal y el borde de la hoja hay un espacio de unos $0.5 \mathrm{~m} . \mathrm{m}$. El peciolo es comprimido, de unos $2 \mathrm{~cm}$. de longirud.

Son coriáceas, flexibles cuando frescas, y rígidas y quebradizas cuando secas. Por transparencia se ven numerosas pumtuaciomes translúcidas en toda la superficie del limbo. El color de la hoja es verde pálido glauco; el peciolo y la nervadura mediana son de color rojizo. Su olor recuerda al del cedrón (Lippia citriodora H. B. y $K$.), como su nombre específico lo indica. Su sabor es aromático, bastante picante, ligeramente amargo y astringente.

Composición química. - Las hojas contienen un aceite esencial que está constituído por 95 por ciento de citronellal $\left(\mathrm{C}^{10} \mathrm{H}^{18}, \mathrm{D}\right)$.

Usos.-La infusión de las hojas se emplea en el Perú, en el tratamiento de la glucosuria.

En Australia, se explota la exudación natural (de color oscuro) del tronco, y constituye uno de los Kinos de Australia; empleados muchas veces, en sustitución de los verdaderos kinos procedentes del Pterocarpus marsupium Roxb, y de la Butea frondosa Roxb. 


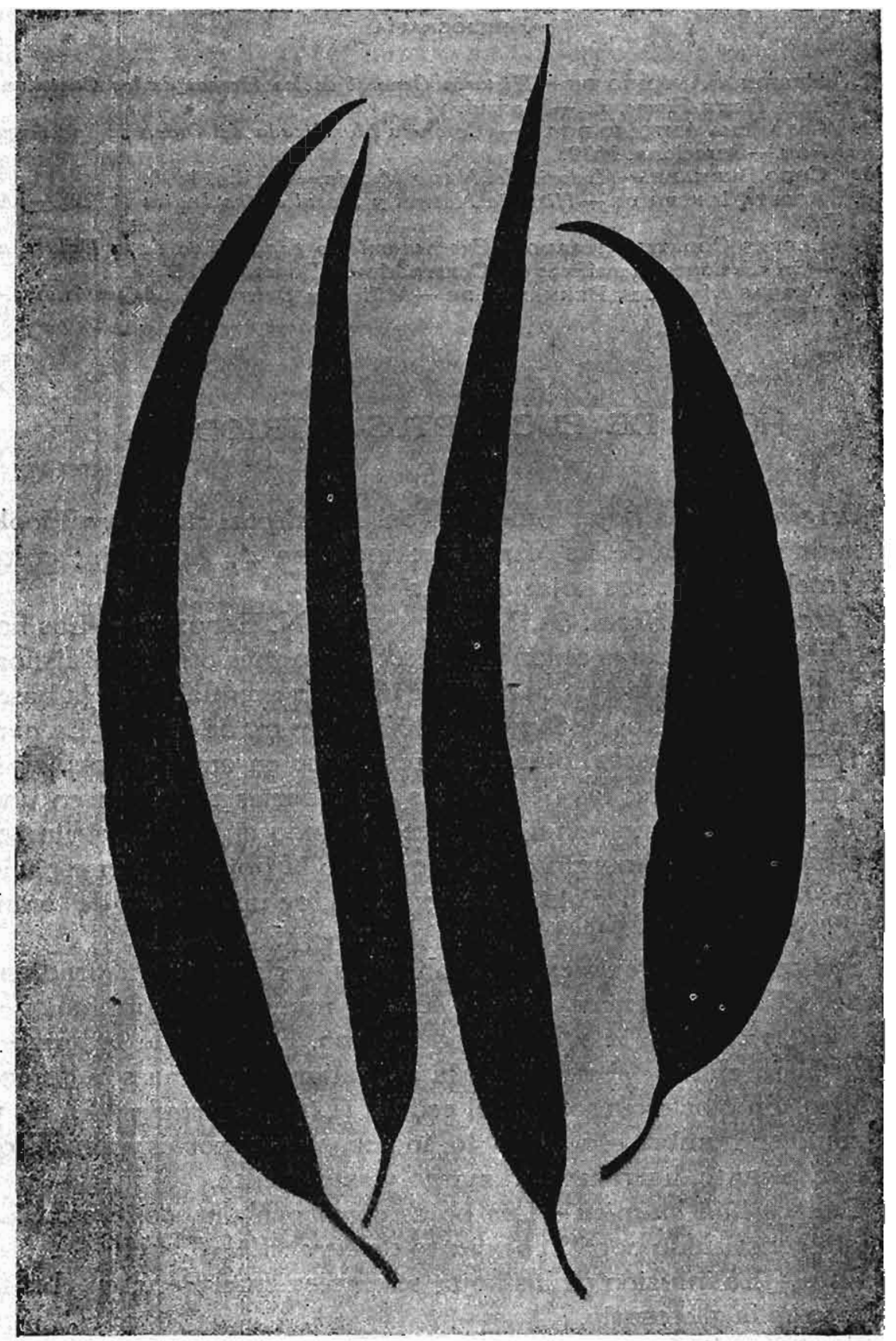

Fig: 7

Eucaliptus, citriodora Hoak

Hojas 


\section{SEMILLAS DE ABRUS PRECATORIUS}

Sin: Gung (Hindu). Gunza (Bombay). Gundumani (Tamul). Piselli d'América, Occhi di granchio, Grani di Jequirity, Piselli da paternostro (Italiano). Jequiriti, Inqueriti (Brazil). Chochito de Indio, Peronilla (Colombia). Huayruro, Huayruru (Perú).

Origen.-Proceden del Abrus precatorius L., planta de la familia de las Leguminosas, sub-familia Papilionáceas; indígena de la India; encontrándosele hoj en las Antillas, Africa, Brazil y en las selvas del Perú.

Es necesario advertir que estas semillas constituyen una variedad de las que en el Perú se denomina Huayruro; aunque más propiamentc se llaman Huayruros, a las semillas de color rojo y negrn de varias especies del género Erythrina.

Historia.-Esta planta, según Flückiger y HaNbùry es conocida désde la más remota antigüedad, pues según ellos está mencionada "en los escritos médicos Sanscritos de Susrula"; habiendo sido empleadas de preferencia las raices, las que hoy sirveri para soIisticar las raíces del Clycyrrhiza glabra $L$.

Caracteres exieriores.--Semillas redondeadas, ovaladas, de 3-6 m.m. en su diámetro mayor; espermodermo de color rojo brillante, con una mancha casi circular, de color negro brillante, sobre el ombligo; duras. Cotiledones plano-convexos.

Composición química.---Están constituídas por Abrina (Jequiritina) la que para SidNeY MARTín es una mezcla de abrus albúmina y abrus globulina: ácido ábrico; materias colorantes; aceite esen. cial; materias alhuminoídicas; sustancia grasa; etc.

La abrina, es una toxialbúmina o fitotoxina, descubierta en 1884 por WARDEN y WADDEL; amorf́a; soluble en el agua y en la glicerina; soluble en la solución acuosa de cloruro de sodio; insoluble en el etanol, éter sulfúrico, cloroformo y bencina; se altera a los $85^{\circ} \mathrm{C}$. Es extremadamente tóxica; semejándose su acción fisiológica a la producida por la ricina, toxialbúmina del Ricinus communis $L$.

Inmunizando animales con abrina se obtiene un suero antitoxico específico, que neutraliza exclusivamente la abrina, y no tiene acción sobre la ricina; probando esto, que aunque ambas son de naturaleza albuminoídica, son distintas.

Usos.-La maceración acuosa ( 3 a $5 \%$ ) en frío, o a $50^{\circ} \mathrm{C}$, durante 24 horas, de las semillas en polvo, se emplea para combatir la conjuntivitis granulosa; pero como el tenor de abrina en las semillas 
es variable y por lo mismo su control dificil, se recomiendan las soluciones standardized, en las que se ha regulado la acción, por medio del suero aratitoxico.

La abrina se emplea en soluciones acuosas al 1 p. 500.000.

Junto con las semillas de varias especies del género Erythrina, se emplean, para hacer collares y en muchos objetos de joyería.

\section{HOJAS Y FLORES DE CEDRON}

Origen.-Proceden de la Lippia citriodora, H. B. K., planta de la familia de las Verbenáceas; indígena de la América Meridional; cultivada en los jardines y huertas como planta medicinal y de adorno (valles de la costa y valles muy templados de la sierra).

Según el padre Gonzales Laguna, de Chile se trajeron a Lima, pies de plantas por los años de 1764 a 1794 (1); pero nosotros creemos que esta planta es también indígena del Perú.

Caracteres exteriores. - Ramas lampiñas, semibrillantes, de color verde o verde rojizo, con tres surcos longitudinales en cada entrenudo, los bordes de los surcos están recorridos (cada uno) por una breve costilla. Ramas jóvenes, muy brevemente y escasamente vellosas y glandulosas y cuando adultas presentan a veces lentejuelas más o menos pronunciadas. Hojas ternado-verticiladas, a veces 4 verticiladas; brevemente pecioladas; de unos $8 \mathrm{ctm}$. de largo por unos $2 \mathrm{ctm}$. de ancho; lanceoladas, atenuadas en el ápice y casi bruscamente atenuadas en la base; finamente dentadas en el margen; más o menos encorvadas hacia abajo; la nervadura mediana es muy gruesa y saliente en la cara inferior; las nervaduras secundarias paralelas, numerosas y muy delgadas, salientes en la cara inferior y formando un ángulo casi recto con la nervadura mediana, sobre todo en la mitad inferior; la cara superior es áspera y de color verde subido y está cubierta de pelos breves cónicos, encorvados hacia los bordes; la cara inferior es lampiña. de color verde pátido y está cubierta de pequeñas glándulas pediceladas, muy brillantes: en la cara superior también se vén estas glándulas pero en menor abundancia.

Estas hojas se caracterizan principalmente por «la presencia de pelos unicelulares cónicos y encorvados, rígidos, rodeados en la base por células inscrustadas de sales calizas que son la causa de la asper idad que presentan sus superficies cuando se pasa la ma- 
no por ellas, y numerosos pelos glandulosos, sobre todo en el epidermo inferior. Las glándulas de estos pelos son cuadricelulares, grandes, esféricas, sentadas o sostenidas por un pedicelo muy corto unicelular. Además, y esto es muy notable, se ven algunas glándulas unicelulares en el extremo de un pelo formado por muchas células sobrepuestas y uniseriadas. Todas estas glándulas, contienen aceite esencial». (Gómez Pamo JuAN R. Tratado de Materia Farmacéutica Vegetal.-Madrid 1906. Tomo I. pág. 814).

Su consistencia es membranáceo-semidura.

Peciolo encorvado, acanalado en su cara superior, de unos $5 \mathrm{~m}$. m. de largo.

Olor aromático muy agradable que recuerda mucho al de las hojas del naranjo y del limón. Sabor aromático pronunciado; agradable que recuerda a! de la cáscara de limón.

Flores pequeñas dispuestas en espigas laxifloras, reunidas de 3 en 3 en verticilo (a veces de 4 en 4 ); formando una panoja terminal constituída por espigas verticiladas. Raquis brevemente y escasamente velloso y glanduloso. Cáliz brevemente velloso, glanduloso y tubuloso, terminado por cuatro dientes breves. Corola subhipocraterimorfa; tubo de color violáceo lilacino, ampliado en la parte superior; limbo dividido en cuatro lóbulos redondeados en el ápice, de color blanco ligeramente violáceo. Estambres cuatro didinamos, los dos breves son inclusos y los dos largos sub-inclusos. Ovario bilocular; velloso en la parte superior, principalmente; con un óvulo en cada celdilla. Estilo incluso, terminal, insertado en un lado del ovario; ensanchado en la parte superior. Estilo bilovulado, inclinado. Brácteas muy breves, anchas y muy bruscamente puntiagudas; su longitud alcanza a la mitad del cáliz más o menos.

El olor y sabor como el de las hojas.

Usos.-La infusión $(10 \times 1000)$ de hojas y flores frescas, se emplea como carminativa, antiespasmódica y estomáquica.

\section{Bibliografía}

1. Gonzales laguna Francisco.-Memoria de las plantas extrañas qué só cuttiuan en Lima, introductidas en los ultimos 30 años hasta el de 1794..-EH Antiguo Mercurio Peruanox.-Edición Fuentes.-Lima, 1861. 


\section{HOJAS DE MELISA}

\section{N. V. Toronjil.}

Origen.-Proceden de la Melissa officinalis L., planta de la lamilia de las Labiadas: originaria de Europa y cultivada en los jardines y huertas del Perú como planta medicinal y de adorno. Muy rara vez alcanza a florecer.

Caracteres exteriores.-Planta herbácea perenne, cespedosa; con tallos lampiños, cuadrangulares, rastreros y radiantes en su base, a veces retorcidos en su base, surcados sobre dos lados opuestos en cada entrenudo.

Hojas opuestas, largamente pecioladas, ovaladas y acorazonadas en la base, terminadas en un diente más o menos obtuso; dentadas; velloso-hispidas en ambas caras, siendo más abundantes los pelos en la cara superior; en la cara inferior sólo se encuentran pelos en la nervadura mediana y en las nervaduras secundarias y aún escasos. Los pelos del limbo de la hoja son largos, pluricelulares, terminados en punta y ligeramente oblícuos. En la cara inferior se observan puntuaciones brillantes que no son sino glándulas secretoras de aceite esencial.

El peciolo es acanalado, débilmente pestañoso, membranoso en sus bordes, de unos $4 \mathrm{ctm}$. de largo generalmente, por unos $2 \mathrm{~m} . \mathrm{m}$. de ancho en su base; de color verde muy pálido.

El limbo de la hoja es de unios $6 \mathrm{ctm}$. de largo por 5 y $1 / 2 \mathrm{ctm}$. de ancho; de color verde subido en la cara superior y verde claro en la inferior.

Las nervaduras son salientes en la cara inferior. La primera pareja de nervaduras secundarias arranca de la base, formando así una hoja trinervia; y las nervaduras secundarias sucesivas, son gradualmente mas débiles y alternadas entre ellas, formando ángulos agudos con la nervadura mediana; las nervaduras de 3 er y $4 .^{\circ}$ orden se anastomosan entre ellas, formando un retículo bastante pronunciado y dejando entre sí mallas bastante anchas, las últimas ramificaciones rematan en el ápice de cada diente.

Estrujándolas ligeramente, despiden un olor aromático agradable, que recuerda al del limón, de la yerba Luisa y del cedrón. Su sabor es herbáceo y aromático.

Composición química.-Las hojas contienen según varios autores: 0.02 por ciento de resina amarga; 1 por ciento de aceite esencial, llamado esencia de melisa; mucílago; tanino; etc. 
La esencia de melisa es utilizada desde el siglo XVI (1); habiendo sido estudiada por primera vez por SCHLLTz (1839), por HoffMANN y por DEHNE (1879).

La esencia de melisa es de color pálido. lluida, de olor agradable, de sabor picante aromático; soluble en el alcohol de $90^{\circ} \mathrm{C}$. ; densidad a $15^{\circ} \mathrm{C}=0.879-0.908$; está constituídá principalmente por cilral $\left(\mathrm{C}^{10} \mathrm{H}^{16} \mathrm{O}\right)$ y citronellal $\left(\mathrm{C}^{10} \mathrm{H}^{18} \mathrm{O}\right)$. (1).

Usos.- Las hojas se emplean en infusión (10 por 1000), como carminativo, antiespasmódico-sedativo y estomáquico.

BIBIIOCRAREA

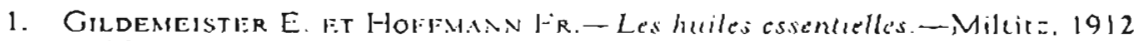
(deuxieme édition).

\section{HOJAS Y FLORES DE MALVA}

Origen.-Proceden de la Lavalera arborea $L$., de la familia de las Maloáceas; planta anua! o hisanual; indígena de Europa. Cultivada en huertas y jardines del Perú como planta medicinal; encontrándosele también semij-silvestre.

Planta semi-herbácea, con tallos derechos, que generalmente llegan hasta $2 \mathrm{~m}$. de altura.

Caraiteres exteriores.-Hojas alternas estipuladas, largamente pecioladas, paimatilobuladas, acorazonadas en la base, onduladas; vellosas en ambas caras; de color verde oscuro en la cara superior y verde pálido en la cara inferior; nervaduras primarias y secundarias salientes en la cara inferior.

Peciolo plano por la parte superior y convexo en la inferior, velloso, de color verde pálido, de unos $15 \mathrm{ctm}$. de largo.

El borde de la hoja es más o menos superficialmente dentado.

En las hojas del tallo, los tres lóbulos superiores de la hoja son sub-obtusos y los dos laterales son generalmente redondeados.

En las hojas de las ramas, los 5 lóbulos son sub-agudos y con los bordes finamente dentados.

El limbo de las hojas del tallo alcanza unos $10 \mathrm{ctm}$. de largo, por unos $12 \mathrm{ctm}$. de ancho; con peciolo de unos $15 \mathrm{ctm}$. El limbo de las hojas de las ramas, mide unos $6 \mathrm{ctm}$, de largo, por unos $7 \mathrm{ctm}$. de ancho; con un peciolo de $7 \mathrm{ctm}$. de largo. 
De consistencia membranácea, muy blandas; inodoras; de sabor mucilaginoso.

Flores axilares; dispuestas en grupos de varias flores, o tan sólo de una o tres lïbres, $y$ otras reumidas de tres a cinco en una pseudountibela.

La flor está constituída por un cáliz de color verde pálido, campanulado gamosépalo; terminado por cinco dientes triangulares, algo alargados, brevemente vellosos; y provisto en su interior de un invólucro o calíeulo de color verde oscuro, campanulado, velloso en ambas caras, formado de tres brácteas soldadas hasta la mitad $y$ redondeadas en su parte libre.

La corola es anchamente campanulada formada de cinco pétalos, anchamente tras-ovalados, soldados por uñuelas por medio del tubo estaminal.

El andróceo está constituído por muchos estambres soldados en un tubo; el ovario está constituído por cinco o más carpelos dispuestos en verticilo, terminados por otros tantos estilos delgados, casi de doble largo del tubo estaminal que rematan en estigmas vellosos unilaterales.

Los pétalos son de color rosado; con la uñuela morado oscuro, terminada generalmente por cinco líneas del mismo color y divergentes.

El fruto es seco, está formado por 5 o más carpelos monospermos; la sémilla es arriñonada.

Flores inodoras, de sabor mucilaginoso.

Usos.-Las flores se emplean en infusión como pectorales.

Las hojas se emplean en cocimiento, o en cataplasmas (bien rrolidas) como emolientes. 